\title{
A Study on the Influence of University Teachers' Social Network on Their Entrepreneurship Intention
}

\author{
Shibin Ma ${ }^{1,}$ a , Jingjing Zhao ${ }^{1, b}$, *, Yong Wang ${ }^{1, c}$ \\ ${ }^{1}$ School of Economics and Management, Nanjing University of Science and Technology, Nanjing210000, \\ China \\ a478659348@qq.com,b,zjj_fsa@163.com,,973575944@qq.com,
}

Keywords: Social network, Entrepreneurial attitude, Entrepreneurial intention, University teachers.

\begin{abstract}
This paper constructs the research model of "social network-entrepreneurial attitude-entrepreneurial intention ", with 184 college teachers in Nanjing as the research sample. The results show that: (1) The individual network, government support network and business network has a significant positive effect on entrepreneurial intention of university teachers, which affect the individual network the biggest role, followed by the commercial network, government support network with minimal impact. (2) Entrepreneurial attitude plays an intermediary role in the process of social network influencing entrepreneurial intention, and even mediates the role of government supporting network and entrepreneurial intention.
\end{abstract}

\section{Introduction}

In order to promote economic growth and improve the macroeconomic environment (Qiu Qiong, GAO Jian, 2004), after the 18th CPC National Congress, the new government clearly put forward the strategy of "public entrepreneurship, innovation". Moreover, under the call of the national policy, governments at all levels attach great importance to entrepreneurial innovation, especially the entrepreneurial innovation of scientific and technological talents (Jiang Jianqiang, Lu Dongyi, 2015). However, the current research on entrepreneurial innovation focused on college students or social workers (Chen Chengwen, Sun Qi Ting, 2009), ignoring the strong scientific research strength of university teachers. In fact, the university, as a gathering place for all kinds of scholars and scientific research, is a high-yielding hatchery of scientific research, and it has a very important position in the entrepreneurial system (Etzkowitz, 2011).

However, there has been a long history of the gap between scientific research and economic development in our country. The success rate of scientific research achievements is very low (Yin Fenglin, 2015). Therefore, how to promote the transformation of scientific research has become a scholar and government issues of common concern. University teachers as the scientific research and invention of the patent owner, at the same time have a good R \& D team and a wide range of social relations based, so its entrepreneurial success rate greatly improved. Therefore, we infer that to promote university teachers to go out to entrepreneurship can effectively promote the industrialization of university research results.

\section{Literature Review and Hypothesis}

Social network (SN). Barnes first proposed the term of "social network" in 1954 and viewed the social network as an informal relationship between individuals. According to previous studies, Adler and Kwon (2002) conducted a comprehensive and systematic definition of the social network, that the social network is different between individuals (including organizations) through social relations to form a relatively stable system. Based on this, we argues that the social network of 
university teachers refers to the sum of various social relations established by university teachers and relatives and friends, industry market, academic circle, government department and entrepreneurial association. This paper will examine the social network of university teachers from four aspects: individual network (IN), government support network (GN), commercial network (CN) and academic network (AN).

Entrepreneurial attitude (EA). Attitude is an active or negative evaluation of individual behavior on a particular act (Ajzen, 1991), and entrepreneurial attitudes are positive or negative evaluations that individuals hold as an entrepreneur, including not only emotional evaluations, but also the evaluation of entrepreneurial results (Liñán and Chen, 2009). Therefore, this paper defines the entrepreneurial attitude of university teachers as their positive or negative evaluation of becoming an entrepreneur.

Entrepreneurial intentions (EI). Intention is the degree to which a person is committed to a particular goal in the future, and thus the degree of commitment to the business is the entrepreneurial intention (Krueger, 1993). Therefore, this paper argues that the entrepreneurial intention of university teachers is that the university teachers consciously want to set up a new enterprise and plan to put it into practice at a certain time in the future.

SN and EI. Social resource theory that resources can not only be occupied by the individual can also be embedded in the social network, network members can be obtained through social relations to its use and use. University teachers can benefit from their social network, gain information and support to commercialize their research. Based on this, the following assumptions are made:

Hypothesis1 (1a, 1b, 1c, 1d). SN (IN, GN, CN, AN) has a positive impact on the EI of university teachers.

SN and EA. The beliefs acquired by scholars through their social networks may have a positive impact on their entrepreneurial attitudes. (Hindle et al., 2009).Family members and close friends have an impact on personal values, attitudes and skills (Chang et al., 2009). All the incentives and policy support from the government help to improve the entrepreneurial attitude of scholars (Bourelos et al., 2012). In addition, knowledge or experience of commerce needs through intimate interaction with business partners helps to develop a positive attitude towards entrepreneurship (Shane, 2000). Moreover, attending professional forums and seminars will help to share information and continue education with people with common language, thus influencing their attitudes and behavior (Salancik and Pfeffer, 1978). We thus propose the following hypothesis.

Hypothesis2 (2a, 2b, 2c, 2d). SN (IN, GN, CN, AN) has a positive impact on the EA of university teachers.

EA and EI. Attitudes can predict intentions and behaviors significantly. If a person shows a positive attitude towards something, then his inner will have a strong interest in it, and the possibility of doing it will be greatly improved. Entrepreneurship is also the case, those who have a positive attitude towards entrepreneurial activity and scientific knowledge of business development are often better able to plan time, energy and resources (Liñán \& Santos, 2007), have a higher business intentions and entrepreneurial possibilities. That is to say, entrepreneurial attitude can significantly predict entrepreneurial intention (Shapero, 1982; Linan \& Chen, 2009; Fritsch \& Krabel, 2012). Therefore:

Hypothesis3. EA has a positive impact on the EI of university teachers.

The mediating role of EA. From the theory of ternary interaction, the entrepreneurial attitude as a cognitive variable is bound to be influenced by the environmental variables of the social network, and the entrepreneurial intention as the behavior prediction is also affected by the entrepreneurial attitude of the cognitive variable. The value and beliefs that scholars acquire through their social network may have an impact on his entrepreneurial attitude, thereby increasing their entrepreneurial intentions and facilitating the participation of scholars in the transformation of knowledge outcomes (Ponomariov and Boardman, 2008). When scholars can get the support and help they need from their social network, their attitudes towards entrepreneurship will become more positive and their entrepreneurial intentions will increase. We thus propose the following hypothesis.

Hypothesis4 (4a, 4b, 4c, 4d). The effect of $S N(I N, G N, C N, A N)$ on EI was mediated by EA. 


\section{Measurement}

\subsection{Methods}

Data collection. This study used questionnaire survey to obtain data, with universities in Nanjing teachers as the research object. In the middle of September 2016, the pretest survey was completed, 50 questionnaires were issued and 44 valid questionnaires were obtained, and the effective questionnaire recovery rate was $88 \%$. The formal questionnaire survey was completed from late September 2016 to late October 2016. A total of 218 questionnaires were collected and 184 valid questionnaires were obtained. The effective recovery rate was $84.4 \%$.

SN measurement. The scale of the individual network was measured by Liñán and Chen (2009), and the IN was measured from family members, colleagues and friends. The Cronbach's $\alpha=0.907$. The scale of the GN was measured in Gelard and Saleh (2011), which was measured from three aspects: government incentives, tax policy support, and economic development. The Cronbach's $\alpha=0.742$. The scale of measuring $\mathbf{C N}$ is based on the study of Fernández-Pérez et al. (2015), which is measured from four aspects: potential consumers, potential suppliers, potential competitors, and potential partners. The Cronbach's $\alpha=0.939$. The scale of the measurement of $\mathbf{A N}$ is based on the study of Ozgen and Baron (2007). There are three aspects: industry conference, professional journal and peer exchange. In this paper, all scales were measured using the Likert 7-point scale. The Cronbach's $\alpha=0.805$.

EA measurement. The study of EA mainly draws on Liñán and Chen (2009) studies, which contain five questions that focus primarily on the individual values of scholars to entrepreneurs, including emotional and evaluation factors, the scale of Cronbach's $\alpha=0.948$.

EI measurement. A survey of entrepreneurial intentions refers to the study of Fernández-Pérez et al. (2015), which contains four questions that are designed to determine the likelihood that scholars will start their business in the next five years, The Cronbach's $\alpha=0.928$.

In addition, this article also based on previous studies, the university teachers of gender, age, title, professional background and whether the patent as a control variable.

\subsection{Data and Analysis}

Validity. We use AMOS 17.0 for the confirmatory factor analysis, the results shown in Table 1, can be seen from the table, the scale of the fitness indicators are within the acceptable range, indicating that the scale of this study has Good aggregation validity and discriminant validity.

\begin{tabular}{llllllll}
\multicolumn{7}{c}{ Table 1 CFA analysis results $(\mathrm{N}=184)$} \\
\hline$\chi^{2} / \mathrm{df}$ & GFI & AGFI & CFI & NFI & IFI & RMR & RMSEA \\
\hline 1.488 & 0.988 & 0.978 & 0.989 & 0.987 & 0.989 & 0.018 & 0.031 \\
\hline
\end{tabular}

Descriptive statistics and correlations. As shown in Table 2, the correlation coefficients of the four dimensions of social network (IN, GN, CN, AN) are 0.658,0.469,0.591,0.477, and all significant in $1 \%$ Level, indicating that the four dimensions of social network and business intentions have a significant moderate positive correlation. The correlation coefficients of individual network, government support network, commercial network, academic network and entrepreneurial attitude of social network is $0.622,0.433,0.479$ and 0.500 respectively, and all of them are significant at $1 \%$ significance level, there are significant moderate positive correlations between the four dimensions of the network and the entrepreneurial attitude. There is a significant positive correlation between entrepreneurial attitudes and entrepreneurial intention $(r=0.830, p<0.01)$. The results of correlation analysis are in good agreement with the hypothesis of this paper. 
Table 2 Descriptive statistics of the variables and Pearson correlation coefficient matrix $(\mathrm{N}=184)$

\begin{tabular}{|c|c|c|c|c|c|c|c|c|c|c|c|}
\hline Variables & IN & GN & $\mathrm{CN}$ & AN & EA & gender & age & title & $\begin{array}{l}\text { professional } \\
\text { background }\end{array}$ & patent & EI \\
\hline IN & - & & & & & & & & & & \\
\hline GN & $.471^{* *}$ & 1 & & & & & & & & & \\
\hline $\mathrm{CN}$ & $.522^{* *}$ & $.403^{* *}$ & 1 & & & & & & & & \\
\hline AN & $.481^{* *}$ & $.371^{* *}$ & $.610^{* *}$ & 1 & & & & & & & \\
\hline EA & $.622^{* *}$ & $.433^{* *}$ & $.479^{* *}$ & $.500^{* *}$ & 1 & & & & & & \\
\hline Gender & $.216^{* *}$ & .144 & .133 & .085 & $.291^{* *}$ & 1 & & & & & \\
\hline Age & -0.073 & 0.106 & -0.038 & -0.103 & $-.194 * *$ & 0.014 & 1 & & & & \\
\hline Title & -.024 & .122 & .028 & $-.179^{*}$ & $-.207^{* *}$ & .087 & $-.645^{* *}$ & 1 & & & \\
\hline $\begin{array}{l}\text { Professional } \\
\text { background }\end{array}$ & .123 & .006 & $.185^{*}$ & .047 & .090 & -.143 & .066 & -.140 & 1 & & \\
\hline Patent & .118 & .127 & $.182^{*}$ & .128 & .082 & $.189^{*}$ & $-.198^{* *}$ & $.319^{* *}$ & -.059 & 1 & \\
\hline EI & $.658^{* *}$ & $.469^{* *}$ & $.591^{* *}$ & $.477^{* *}$ & $.830^{* *}$ & $.351^{* *}$ & -.128 & -.063 & .067 & .139 & 1 \\
\hline
\end{tabular}

\section{Regression analysis}

a. $* \mathrm{P}<0.05 ; * * \mathrm{P}<0.01$.

Can be seen from the table 3, in the four dimensions of the introduction of social network model, 2 more than 1 of the explanatory power of the model significantly increased by $35.8 \%(\mathrm{R} 2=0.358)$. The adjusted decision coefficient R2 is 0.506 , which indicates that the four dimensions of social network can explain $50.6 \%$ of University Teachers' entrepreneurial attitude. From the results, it is assumed that $\mathrm{H} 2 \mathrm{a}$ has been validated $(\beta=0.376, \mathrm{p}<0.01)$. Suppose $\mathrm{H} 2 \mathrm{~b}$ has been verified $(\beta=0.150$, $\mathrm{p}<0.01)$. Suppose $\mathrm{H} 2 \mathrm{c}$ has been verified $(\beta=0.125, \mathrm{p}<0.10)$. Suppose $\mathrm{H} 2 \mathrm{~d}$ has been verified $(\beta$ $=0.129, \mathrm{p}<0.10)$.

Table 3 The regression analysis result for $\mathrm{SN}$ on EA $(\mathrm{N}=184)$

\begin{tabular}{|c|c|c|c|c|c|c|}
\hline & \multicolumn{3}{|c|}{ MODEL 1} & \multicolumn{3}{|c|}{ MODEL 2} \\
\hline & $\mathrm{B}$ & $\beta$ & $\mathrm{P}$ & $\mathrm{B}$ & $\beta$ & $\mathrm{P}$ \\
\hline Gender & .848 & $319^{* *}$ & .000 & .498 & $.187^{* *}$ & .001 \\
\hline Age & -.356 & -.129 & .120 & -.283 & -.102 & .108 \\
\hline Title & -.524 & $.322 * *$ & .000 & -.438 & $.269 * *$ & .000 \\
\hline Professional background & .099 & .102 & .146 & .007 & .007 & .893 \\
\hline Patent & .252 & .096 & .194 & .007 & .003 & .961 \\
\hline IN & & & & .394 & $.376^{* *}$ & .000 \\
\hline GN & & & & .198 & $.150 *$ & .017 \\
\hline $\mathrm{CN}$ & & & & .132 & .125 & .088 \\
\hline $\mathrm{AN}$ & & & & .149 & .129 & .074 \\
\hline $\mathrm{R}^{2}$ & .172 & & & .530 & & \\
\hline Adj. $R^{2}$ & .149 & & & .506 & & \\
\hline $\mathrm{F}$ & 7.384 & & & 21.80 & & \\
\hline$\Delta \mathrm{R}^{2}$ & .172 & & & .358 & & \\
\hline The $F$ value of $\Delta R^{2}$ & 7.384 & & & 33.16 & & \\
\hline
\end{tabular}

As can be seen from Table 4, after the introduction of entrepreneurial attitude, the coefficient $\mathrm{R}^{2}$ is 0.713 , the overall regression model $\mathrm{F}$ is 73.345 , and is significant at 0.01 level, so the model 2 has a good fit; $(\Delta \mathrm{F}=341.909, \mathrm{p}<0.01)$. The adjusted coefficient $\mathrm{R}^{2}$ is 0.703 , which indicates that the entrepreneurial attitude can explain the relationship between the university teachers and entrepreneurship, and the explanatory power of model 2 is significantly higher than that of model 1 $70.3 \%$ of the intention. From the results of regression analysis, entrepreneurial attitudes have a significant positive effect on the entrepreneurial intention of university teachers $(\beta=0.818, p<0.01)$. Therefore, it is assumed that $\mathrm{H} 3$ is validated. 
Table 4 The regression analysis results for EA on EI $(\mathrm{N}=184)$

\begin{tabular}{|c|c|c|c|c|c|c|}
\hline & \multicolumn{3}{|c|}{ MODEL 1} & \multicolumn{3}{|c|}{ MODEL 2} \\
\hline & $\mathrm{B}$ & $\beta$ & $\mathrm{P}$ & $\mathrm{B}$ & $\beta$ & $\mathrm{P}$ \\
\hline Gender & 1.002 & $.362 * *$ & .000 & .279 & $.101 *$ & .023 \\
\hline Age & -.206 & -.072 & .391 & .098 & .034 & .490 \\
\hline Title & -.261 & -.154 & .073 & .186 & $.109 *$ & .036 \\
\hline Professional background & .108 & .106 & .131 & .024 & .023 & .576 \\
\hline Patent & .294 & .107 & .150 & .079 & .029 & .511 \\
\hline EA & & & & .852 & $.818^{* *}$ & .000 \\
\hline $\mathrm{R}^{2}$ & .159 & & & .713 & & \\
\hline Adj. $R^{2}$ & .135 & & & .703 & & \\
\hline $\mathrm{F}$ & $6.734^{*}$ & & & 73.3 & $* *$ & \\
\hline$\Delta \mathrm{R}^{2}$ & .159 & & & .554 & & \\
\hline The $F$ value of $\Delta R^{2}$ & $6.734^{*}$ & & & 341. & $9 * *$ & \\
\hline
\end{tabular}

In Table 5, the control variables, the four dimensions of social networks and entrepreneurial attitudes were put into the regression equation. Can be seen from the table5, in the four dimensions of the introduction of social network, model 2 more than 1 of the explanatory power of the model significantly increased by $42.7 \%(\mathrm{R} 2=0.427)$; the adjusted coefficient of determination $\mathrm{R} 2$ was 0.565 , showed that the four dimensions of social network can explain academic entrepreneurial intention $56.5 \%$. From the results of regression analysis, H1a was verified $(\beta=0.376, p<0.01)$. H1b was verified $(\beta=0.138, p<0.05)$. H1c was verified $(\beta=0.305, p<0.01)$. The impact of Academic Network on entrepreneurial intention of academic entrepreneurs has not been verified by significance, so H1d has not been verified.

In the introduction of entrepreneurial attitude, model 3 than model 2 explanatory power significantly increased by $18.4 \%(\mathrm{R} 2=0.184)$. From the regression analysis results, after adding entrepreneurial attitude, coefficient of individual network was significantly decreased ( $\mathrm{P}$ decreased from 0.376 to $0.141, \mathrm{p}<0.01$ ), so the entrepreneurial attitude plays a partial mediating role between the individual network and entrepreneurial intention, $\mathrm{H} 4 \mathrm{a}$ partially verified. The government support network has become significantly less significant, so entrepreneurial attitude plays a fully intermediary role between government support network and entrepreneurial intention, and $\mathrm{H} 4 \mathrm{~b}$ has been verified. The coefficient of business network was significantly reduced ( $\beta$ was reduced from 0.305 to $0.237, \mathrm{p}<0.01$ ), so entrepreneurial attitude played a partial intermediary role between business network and entrepreneurial intention, and $\mathrm{H} 4 \mathrm{c}$ was partially verified. Because the academic network has no significant influence on entrepreneurial intention, H4d has not been verified.

Table 5 The regression analysis result of the mediator role for $\mathrm{EA}(\mathrm{N}=184)$

\begin{tabular}{|c|c|c|c|c|c|c|}
\hline & \multicolumn{3}{|c|}{ MODEL 2} & \multicolumn{3}{|c|}{ MODEL 3} \\
\hline & B & $\beta$ & $\mathrm{P}$ & B & $\beta$ & $\mathrm{P}$ \\
\hline Gender & .601 & $217^{* *}$ & .000 & .277 & $.100^{*}$ & .013 \\
\hline Age & .165 & .057 & .336 & 019 & .007 & .883 \\
\hline Title & .222 & $.131^{*}$ & .040 & .063 & .037 & .455 \\
\hline Professional background & .023 & .022 & .664 & .028 & 027 & .484 \\
\hline Patent & .009 & .003 & .953 & .004 & .001 & .971 \\
\hline IN & .411 & $.376^{* *}$ & .000 & .154 & $.141^{*}$ & .006 \\
\hline GN & 190 & $.138^{*}$ & .018 & .061 & .045 & .314 \\
\hline $\mathrm{CN}$ & .337 & $.305^{* *}$ & .000 & 251 & $.227^{*}$ & .000 \\
\hline AN & .025 & .020 & .762 & .072 & .060 & .237 \\
\hline EA & & & & .651 & $.625^{*}$ & .000 \\
\hline $\mathrm{R}^{2}$ & .586 & & & .770 & & \\
\hline Adj. $R^{2}$ & .565 & & & .756 & & \\
\hline $\mathrm{F}$ & 27.38 & & & 57.82 & & \\
\hline$\Delta \mathrm{R}^{2}$ & .427 & & & .184 & & \\
\hline The $F$ value of $\Delta R^{2}$ & 44.89 & & & 137.8 & $73^{* *}$ & \\
\hline
\end{tabular}




\section{Summary}

Research conclusions. Through empirical analysis, this paper verifies that individual network, government support network and commercial network have significant positive influence on entrepreneurial intention of University teachers. Among them, the individual network has the most significant influence, followed by the commercial network, and the government supported network has the least impact. We speculate that this is because in Chinese people, relatives and friends are the most important people, their opinions are often the first consideration and the most important. This paper has failed to demonstrate significant effect on entrepreneurial intention of university teachers' academic network, the reason we consider the academic atmosphere is strong, scholars have rarely discussed achievements in scientific research practice, and it is difficult to stimulate and collision of inspiration. Moreover, due to the limitation of the concept, many people think that university teachers do poineering work when the boss is a kind of job performance, many entrepreneurial university teachers are reluctant to open their own identity of the entrepreneur or entrepreneurial intention, so the effect is not significant academic network is understandable.

Contributions. The most important contribution is to select university teachers as the research object, provides a new perspective for entrepreneurship research, and the research on Chinese context theory system is helpful to enrich the intercultural study.

The conclusion of this paper is helpful to promote the practice of entrepreneurship. For college teachers, efforts should be made to build their own social network. For colleges and universities, we can strengthen their entrepreneurial intention through policy orientation and school enterprise cooperation. For the government, we should improve the protection of entrepreneurship, strengthen entrepreneurship education, and pay attention to the effect of entrepreneurial platform.

Limitations and future. First of all, to have a strong spirit of the traditional science teacher, the deviation caused by social desirability effect is more obvious. Secondly, this study only takes the psychological characteristics of entrepreneurial attitude variables, but the psychological characteristics include entrepreneurial self-efficacy and entrepreneurial identity, and so on, so the future research can be expanded. Finally, this study does not control the type of University, so subsequent research can be noticed.

\section{References}

[1] Fini R, Grimaldi R, Marzocchi G L, et al. The determinants of corporate entrepreneurial intention within small and newly established firms [J]. Entrepreneurship Theory and Practice, 2012, 36(2): 387-414.

[2] De Carolis D M, Litzky B E, Eddleston K A. Why network enhance the progress of new venture creation: The influence of social capital and cognition $[\mathrm{J}]$. Entrepreneurship theory and practice, 2009, 33(2): 527-545.

[3] Ozgen E, Baron R A. Social sources of information in opportunity recognition: Effects of mentors, industry network, and professional forums [J]. Journal of business venturing, 2007, 22(2): 174-192.

[4] Birley S. The role of network in the entrepreneurial process [J]. Journal of business venturing, 1986, 1(1): 107-117.

[5] Chang E P C, Memili E, Chrisman J J, et al. Family social capital, venture preparedness, and start-up decisions: A study of Hispanic entrepreneurs in New England [J]. Family Business Review, 2009.

[6] Leyden D P, Link AN N, Siegel D S. A theoretical analysis of the role of social network in entrepreneurship [J]. Research Policy, 2014, 43(7): 1157-1163.

[7] Kolvereid L. Organizational employment versus self-employment: Reasons for career choice intentions [J]. Entrepreneurship: Theory and Practice, 1996, 20(3): 23-32. 
[8] Fritsch M, Krabel S. Ready to leave the ivory tower? : Academic scientists' appeal to work in the private sector [J]. The Journal of Technology Transfer, 2012, 37(3): 271-296.

[9] Lee L, Wong P K, Der Foo M, et al. Entrepreneurial intentions: The influence of organizational and individual factors [J]. Journal of business venturing, 2011, 26(1): 124-136.

[10]Kautonen T, Van Gelderen M, Tornikoski E T. Predicting entrepreneurial behaviour: a test of the theory of planned behavior [J]. Applied Economics, 2013, 45(6): 697-707.

[11]Fernández-Pérez V, Alonso-Galicia P E, Rodríquez-Ariza L, et al. Professional and personal social network: A bridge to entrepreneurship for academics? [J]. European Management Journal, 2015, 33(1): 37-47. 